KEY WORDS

Economists

Surveys

Economic policy

Fiscal policy

Competition

Income distribution

Central banks

Mexico

Carlos M. Urzúa

Director of the Graduate School of Public Administration and Public Policy (EGAP), Tecnológico de Monterrey, Mexico City campus

- curzua@itesm.mx
CEPAL REVIEW 91 • APRIL 2007

\section{Consensus and dissension among Mexican economists}

\author{
Carlos M. Urzúa
}

$\mathrm{T}$

his article identifies areas of agreement and disagreement among Mexican economists in relation to key issues of economics, on the basis of a survey of 360 members of the profession. The propositions eliciting the greatest consensus included: equity in income distribution, vigorous use of antitrust and consumer protection laws and the use of countercyclical fiscal policies. The most contentious issues were: private investment in the energy sector, the determinants of inflation, the minimum wage as a cause of unemployment and the objectives to be pursued by an independent central bank. 
I

\section{Introduction}

"If parliament were to ask six economists for an opinion, seven answers would come back-two, no doubt, from the volatile Mr. Keynes. If economists cannot agree among themselves, how can the rest of the world be expected to agree with them and to respect their recommendations?"

Samuelson (1966, p. 1628)
Samuelson's question is a weighty one, although the premise, that economists cannot agree among themselves, deserves the support of some empirical, rather than merely anecdotal evidence. Kearl, Pope and others (1979) were the first to seek such evidence. Using a questionnaire containing 30 questions that were more or less evenly divided between microeconomic and macroeconomic issues, these authors set out to measure the degree of consensus among United States economists in the late 1970s. Not long afterwards, Frey, Pommerehne and others (1984) used a similar questionnaire to identify areas of agreement and disagreement among economists in Austria, France, Germany and Switzerland. The list continued to lengthen thereafter: Block and Walker (1988) conducted a similar study in Canada, then Ricketts and Shoesmith (1992) did the same in the United Kingdom, after which, as Anderson (1998, p. 6) meticulously documents, studies were carried out in Australia, Belgium, New Zealand, Russia, South Africa and 10 countries of East and South-East Asia.

This enumeration immediately raises the question: why were no similar surveys conducted among Spanishspeaking economists at any time during that decade? Since the present author is one of that breed, we shall ignore the possible sociological explanations for this and confine ourselves to noting that, after the turn

\footnotetext{
$\square$ The author is grateful for the assistance of Óscar Guerra Ford and Jorge Luis Álvarez Peralta, who not only hosted the questionnaire on the electronic portal of the National Association of Economists, but took the time to monitor it over eight long weeks. He is also grateful to Fernando Butler, Valeria Castellanos and Mario Sánchez Silva for their suggestions, and to Héctor Sandoval for his computer assistance. Needless to say, the author bears sole responsibility for any remaining errors.
}

of the millennium, Caminal and Rodríguez (2003) remedied the absence of their country from the list by conducting a study on the degree of consensus among Spanish academics. The present study sets out to continue this work for Mexico, apparently the first country in Latin America where a survey has been conducted for this purpose.

The questionnaire required opinions to be expressed on 30 questions concerning matters we considered crucial for the Mexican economy. For the purposes of comparison, we tried to make as many questions as possible similar if not identical (in Spanish translation) to the 30 asked by Kearl, Pope and others (1979). But the years take their toll: Frey, Pommerehne and others (1984) discarded three of those questions as being somewhat dated, and we ended up rejecting a further seven for the same reason. To the 20 questions remaining we added 10 of our own to round out the questionnaire.

Section II that follows presents some aspects of the questionnaire design. Section III then discusses the content of the questionnaire and the basic results obtained, concentrating particularly on those propositions which produced the highest levels of consensus or dissension among economists. After this, section IV analyses response patterns among different groups of people, with a view to ascertaining whether personal characteristics such as age or sex played a significant role in the replies.

Section V then presents an analysis of answers to each of the propositions, following a twofold classification of these. First, they are divided into microeconomic (micro) and macroeconomic (macro) propositions. This makes it possible to evaluate a hypothesis that, a priori, would appear reasonable: micro propositions ought to elicit greater consensus 
than macro ones. The second classification distinguishes propositions that are or tend to be positive ("this can be done") from those that are normative ("this ought to be so"). This is followed by an examination of the hypothesis, plausible on the face of it, that positive proposals command a greater consensus than normative ones. Lastly, factor analysis is used to classify the questions not by a priori economic criteria, but purely on the basis of the statistical information. Section VI, lastly, presents some of the conclusions of this study.

\section{II}

\section{Design and implementation of the survey}

The formal design of the survey followed four rules. The first, an obvious but important one, was that the number of questions should be kept to a minimum to avoid inconveniencing respondents. Also avoided as far as possible was the use of technical jargon that was not common to all generations of economists. For example, rather than refer by name to the real business cycle theory developed by Edward Prescott and his followers, the questionnaire asked whether "economic fluctuations are mainly caused by aggregate supply impacts".

The second rule was that the questions on the respondent's personal characteristics should be at the end of the survey and phrased so as not to be indiscreet. These questions covered just six subjects: age, sex, country of residence, highest educational qualification, where this qualification was obtained, and sector of employment. Questions dealing explicitly with the respondent's ideological or political leanings were deliberately avoided (by contrast with Caminal and Rodríguez, 2003) to forestall any feelings of suspicion. The question about areas of specialization usually asked since Kearl, Pope and others (1979) was also omitted, as it was assumed there would be a great variety of answers given the heterogeneity of the population.

The third rule was that, to avoid so-called "neutrality bias" (when someone does not wish to choose, is uninterested or has no opinion on the subject), a scale of just four possible responses was chosen: strongly disagree, disagree, agree or strongly agree. As Frary (1996, p. 3) establishes: "There is no assurance whatsoever that a subject choosing the middle scale position harbors a neutral opinion. A subject's choice of the scale midpoint may result from: Ignorance, Uncooperativeness, Reading difficulty, Reluctance to answer, or Inapplicability." This runs counter to Likert's original scale, which contains an odd number of options because it includes a midpoint response, and also contrasts, in our context, with the practice of Kearl, Pope and others (1979) and their followers, who often provided just three options, including a midpoint one. The scale for this study was similar to that employed by Caminal and Rodríguez (2003), however.

The final rule for the formal design of the questionnaire was that questions were framed so as to avoid the so-called "halo effect". Under the influence of this effect, an answer to a particular question might be biased if the respondent associated it with some personality, group or political party. For example, although the survey contains propositions on public finance issues, none of them makes any reference to the so-called "new public finances" ("nueva hacienda pública"), a term coined at the start of Vicente Fox's six-year administration (2000-2006).

As a pilot test, a printed version of the questionnaire was distributed among participants at a convention of the National Association of Economists (CNE) in September 2005. The 38 people who completed it (anonymously, as requested) had no objections to the form or substance of the survey. The next step was to design a mechanism for general application of the questionnaire. Although the ideal procedure would have been to treat all the country's economists as the target population and take a random sample, in practice the study population had to be reduced substantially. This was due to a number of factors. To begin with, there was no reliable register of all economists based in Mexico. Nor was a fast, efficient ordinary postal service available. Lastly, there was the need to ensure respondents' anonymity. This last point might seem superfluous at first sight, but it is not in Mexico, where surveys have to be as impersonal as possible to have any prospect of being answered.

For all these reasons, it was decided that the most effective way of presenting the questionnaire was over the Internet, even though this would mean ruling out 
a large number of economists who had no Internet access, many of them in the provinces. Thus, given that segments of the study population were excluded because they had no access to the Internet, and because it cannot be claimed a priori that this exclusion produced no significant biases in the results, the areas of agreement and controversy discussed in this work must be understood to exist among economists who are both Mexican residents and Internet users, rather than all Mexican economists as a group.

The questionnaire was posted on the CNE web portal on an unrestricted access basis during October and November 2005. Invitations to respond were issued in two ways. First, invitations were e-mailed to 432 economists whose addresses were collected from information available on Mexican university portals and from the portals of government offices involved with economic matters (this compilation was exhaustive rather than stratified). Second, CNE representatives in the provinces received personal invitations. Although this variant was not originally provided for in the sample design, the CNE thought it advisable to notify state-level representatives that there was a survey on its portal. How many CNE member economists received the invitation to respond to the survey? In principle, it was received by the presidents of all the state associations (in Mexico there are 31 states plus the Federal District). Although some of them may in turn have invited other members of their associations to answer the survey, there is no evidence that this was done formally in any state. In any event, the anonymous character of the survey and its immediate availability over the Internet means that there can be no assurance that only $464(=432+32)$ economists were aware of its existence. Others may well have been informed about it by some of those who were personally invited by this author or the CNE.

The questionnaire was answered by 360 economists residing in Mexico. ${ }^{1}$ Given all the caveats in the previous paragraph, it is not possible to affirm that the acceptance rate was $78 \%$, as the figures suggest; the actual percentage may have been lower. Nonetheless, we venture to suggest

\footnotetext{
${ }^{1}$ A total of 372 replies were received, but 12 of these were from economists living outside Mexico and so had to be disregarded. Of the other 360 , eight were from computers that did not have a unique ip (Internet protocol) address. However, given that files from the same ip address were different in almost all respects and that the respondents concerned were mainly young, we assumed they were economics students using shared computers to complete the questionnaire.
}

that the acceptance rate was certainly higher than those obtained by Kearl, Pope and others (1979), with 33\% acceptance; Frey, Pommerehne and others (1984), with 45\%; Block and Walker (1988), with 33\%; and Ricketts and Shoesmith (1992), with 36\%. If we are right, we believe that the improvement is due to the ease with which surveys can be responded to over the Internet. Even so, we must acknowledge that non-responders can significantly affect the sample composition.

The profiles of the economists who answered the survey were as follows:

- Age: between 18 and 75, with a median of 42 .

- Sex: $21 \%$ female and $79 \%$ male.

- Academic level: $6 \%$ were degree course students while $22 \%$ had a first degree, $38 \%$ a master's and $34 \%$ a doctorate.

- Place where highest qualification obtained: $68 \%$ in Mexico, 22\% in the United States (or Canada), $8 \%$ in Europe and $2 \%$ in another country or region.

- Sector of employment: $46 \%$ public university, $18 \%$ private university, $14 \%$ federal public sector, $11 \%$ private sector, $9 \%$ state or municipal public sector and $2 \%$ other.

As can be seen from the different educational levels and the high percentage of respondents working in universities, the sample was skewed towards academic economists and somewhat against those working in the private sector, but not against those working in the public sector ( $23 \%$ seems about right). There was also substantial variation in ages and places of study, while the shares of the two sexes would seem to be representative of the target population. Lastly, the percentage of respondents with a postgraduate qualification is certainly too high to be representative of the economist population in general. It will be recalled that, owing to the character of the survey design itself, the study population was limited to economists with Internet access (and an e-mail address available from the Internet). Because most of these work in universities, the likelihood of their being qualified above degree level is much higher than for the general run of economists. 


\section{III}

\section{General results}

Table 1 shows the questionnaire used and the results obtained in terms of response frequencies. It is worth pointing out that of the 30 propositions it included, half relate to microeconomic issues and the other half to macroeconomic ones; in turn, each of these halves divides almost equally into positive and normative propositions. ${ }^{2}$ Again, as mentioned earlier, we tried to make as many questions as possible similar to the 30 asked by Kearl, Pope and others (1979), and again by subsequent authors, but we had to discard 10 of them as obsolete. Translated as literally as possible, the first 20 questions in our questionnaire corresponded to the following questions in Kearl, Pope and others: 1-5, 7, 9-10, 12-16, 18, 20, 23, 25, 26 and 29-30. Questions 21 to 30 in table 1 are new.

The information provided by table 1 would be incomplete if, in addition to the response percentages given there, it did not present a measurement of the degree of agreement or disagreement encountered for each question. Accordingly, relative entropy, symbolized here by $\varepsilon$, was calculated as the measure of disagreement; this is the measure that has been employed in all studies of this type.

The description of this statistic is as follows. Given that the number of categories is always four in our case, if pi denotes the relative frequency for each option, the entropy associated with the range of possible responses for each question is defined as

$$
E=-\sum_{i=1}^{4} p_{i} \log _{2}\left(p_{i}\right)
$$

where, following Shannon, the logarithm is base 2, although the natural logarithm could well be used with very similar results. This entropy function has a maximum of 2 when each of the options is chosen by exactly a quarter of respondents, in which case there is zero consensus and maximum disagreement. Conversely, this function has a minimum of 0 when

\footnotetext{
${ }^{2}$ Section $\mathrm{V}$ gives a detailed presentation of the matrix classification of the propositions identified using these criteria.
}

just one of the four options is selected by everyone, in which case there is maximum consensus. To obtain a range of 0 to 1 for this measure, given that the maximum possible entropy in our case is 2 , we can define relative entropy as $\varepsilon=\mathrm{E} / 2$.

Table 2 presents this entropy for each of the 30 questions. Its last two columns also show the relative entropies obtained in similar surveys in the United States and France. These results correspond to our first 20 questions, as they are similar to those of Kearl, Pope and others (1979). It should be stressed that the results for these two countries are not strictly comparable to ours, since those surveys were conducted over 20 years ago. Nonetheless, we will refer occasionally to these two columns in the discussion that follows, chiefly because of the striking difference between the pattern of consensus in the United States and France, the Mexican case being similar to the latter's.

Tables 1 and 2 contain some results that were predictable and others that were quite unexpected. The two propositions that commanded the greatest consensus (the least entropy in table 2), and indeed the only ones whose median was the extreme response "strongly agree" (in bold in table 1), were propositions 8 , "The distribution of income in and between countries should be more equal" and 9, "Antitrust laws should be used vigorously to reduce monopoly power from its current level". It is not surprising that the first of these should have elicited a high degree of consensus, although it is worth noting that a less general proposition, "Income distribution in the industrialized countries ought to be more equitable", was among those on which United States economists disagreed most among themselves $(\varepsilon=0.88$ in table 2$)$, whereas there was a moderate degree of consensus among French economists.

Again, there is a notably high level of agreement among Mexican economists on the need to apply antitrust laws vigorously. This finding is strengthened when we observe that the proposition which ranked third in terms of consensus (a negative one on this occasion, however) was number 19, "Consumer protection laws generally reduce economic efficiency". That these answers should be so polarized perhaps reflects the great industrial concentration currently seen in key sectors of the economy, and the defencelessness 
TABLE 1

\section{Questionnaire: Response percentages and medians}

(Percentages, medians in bold)

Propositio

$\begin{array}{cccc}1 & 2 & 3 & 4 \\ \begin{array}{l}\text { Strongly } \\ \text { disagree }\end{array} & \text { Disagree } & \text { Agree } & \begin{array}{c}\text { Strongly } \\ \text { agree }\end{array}\end{array}$

1. Tariffs and import quotas reduce general economic welfare

2. The government should be an employer of last resort

3. The money supply is more of an important target than interest rates for monetary policy

4. Cash payments are superior to transfer-in-kind

5. Flexible exchange rates offer an effective international monetary arrangement

6. A minimum wage increases unemployment among young and/or unskilled workers

7. Fiscal policy has a significant effect on a less than fully employed economy

8. The distribution of income in and between countries should be more equal

9. Antitrust laws should be used vigorously to reduce monopoly power from its current level

10. Inflation is primarily a monetary phenomenon

11. The government should base its social policies on a negative income tax when incomes are inadequate

12. Wage-price controls should be used to control inflation

13. A ceiling on rent reduces the quantity and quality of housing available

14. Effluent taxes represent a better approach to pollution control than the imposition of pollution ceilings

15. The level of government spending should be reduced (disregarding expenditures for stabilization)

16. The federal budget should be balanced over the business cycle rather than yearly

17. The redistribution of income is a legitimate task for government

18. In the short run, unemployment can be reduced by increasing the rate of inflation

19. Consumer protection laws generally reduce economic efficiency

20. The economic power of labour unions should be significantly curtailed

21. Every central bank should include employment and/or economic growth among its objectives

22. Genetically modified crops have a positive effect on the economy

23. Economic fluctuations are mainly caused by aggregate supply impacts

24. Direct subsidies to firms are generally unjustifiable

25. The State should tax or control international flows of speculative capital

26. The energy sector should be treated like any other sector where private investment is concerned

27. The more independent the central bank, the better for economic stability and growth

28. Income taxes should be the mainstay of national tax systems

29. Private-sector involvement in the operation of public infrastructure is typically inefficient

30. Nature reserves should be protected even at the price of lower economic growth
9

18

6

4

17

4

1

1

14

14

23

4

5

17

2

43

35

13

40

40

51

33

12

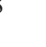

36

7

44

14

52

21

.

38

33

12

57

21

36

60

43

52

35

16

48

8

35

5

28

4

55

23

18

22

53

20

29

11

63

20

2

15

48

40

40

43

5

19

63

17

42

1

5

22

20

38

31

10

10

32

51$$
32
$$

5

57

$$
36
$$

34

43

44

28

43

40

15

47

33

7

5

24

51

20

Source: Prepared by the author. 
TABLE 2

Mexico, the United States and France: Relative entropies

\begin{tabular}{|c|c|c|c|c|}
\hline Proposition & $\begin{array}{c}\text { Mexico } \\
\varepsilon \\
(\%)\end{array}$ & Position & $\begin{array}{c}\text { United States } \\
\varepsilon \\
(\%)\end{array}$ & $\begin{array}{c}\text { France } \\
\varepsilon \\
(\%)\end{array}$ \\
\hline 1 & 87 & 20 & 48 & 85 \\
\hline 2 & 92 & 26 & 84 & 91 \\
\hline 3 & 86 & 18 & 87 & 90 \\
\hline 4 & 84 & 16 & 68 & 90 \\
\hline 5 & 82 & 11 & 63 & 83 \\
\hline 6 & 93 & 27 & 66 & 74 \\
\hline 7 & 78 & 7 & 67 & 69 \\
\hline 8 & 61 & 1 & 88 & 80 \\
\hline 9 & 64 & 2 & 79 & 66 \\
\hline 10 & 94 & 29 & 86 & 66 \\
\hline 11 & 80 & 8 & 71 & 86 \\
\hline 12 & 86 & 18 & 58 & 84 \\
\hline 13 & 80 & 8 & 48 & 86 \\
\hline 14 & 82 & 11 & 84 & 88 \\
\hline 15 & 91 & 25 & 88 & 88 \\
\hline 16 & 69 & 4 & 82 & 87 \\
\hline 17 & 75 & 6 & 81 & 71 \\
\hline 18 & 82 & 11 & 90 & 85 \\
\hline 19 & 68 & 3 & 85 & 50 \\
\hline 20 & 88 & 22 & 87 & 81 \\
\hline 21 & 93 & 27 & $\ldots$ & $\ldots$ \\
\hline 22 & 81 & 10 & $\ldots$ & $\ldots$ \\
\hline 23 & 69 & 4 & $\ldots$ & $\ldots$ \\
\hline 24 & 83 & 14 & $\ldots$ & $\ldots$ \\
\hline 25 & 90 & 23 & $\ldots$ & $\ldots$ \\
\hline 26 & 98 & 30 & $\ldots$ & $\ldots$ \\
\hline 27 & 87 & 20 & $\ldots$ & $\ldots$ \\
\hline 28 & 90 & 23 & $\ldots$ & $\ldots$ \\
\hline 29 & 85 & 17 & $\ldots$ & $\ldots$ \\
\hline 30 & 83 & 14 & $\ldots$ & $\ldots$ \\
\hline
\end{tabular}

Source: Author's own figures and data from Block and Walker (1988, table 4).

of many Mexican consumers. Alongside this, however, it might also be conjectured that these answers had an ideological facet, as both propositions entailed government intervention. Indeed, as table 2 shows, both also commanded a very high degree of consensus among French economists, whereas among those in the United States, with their greater reluctance to countenance government interference, there was more disagreement.

The other two propositions that elicited a high degree of consensus among Mexican economists are classics of the macroeconomic literature: number 16 , on the advisability of a countercyclical policy in government spending, and 23 , on the main cause of economic fluctuations. In the first case, $83 \%$ of respondents agreed that it was advisable to balance the budget over the cycle rather than yearly. This opinion is not only interesting but important too, since it stands in stark contrast to a law passed in early 2006 instructing the Mexican federal government to do just the opposite. Regarding the other proposition, only $38 \%$ agreed that aggregate supply impacts were the main cause of the business cycle (as so-called real business cycle theory suggests), whereas the other $62 \%$ assigned the leading role to changes in aggregate demand (the Keynesian view).

What about the propositions that attracted the least consensus? As might perhaps have been expected in a country where a great deal of controversy has traditionally surrounded the energy sector, the greatest relative entropy was obtained for proposition 26. Opinions were divided almost equally between those who were for private investment in the sector and those who were against it. This polarization extended to the percentages strongly agreeing or disagreeing $(20 \%$ and $18 \%)$.

The second most controversial proposition was number 10 ("Inflation is primarily a monetary phenomenon"), since votes were almost equally divided for and against. It is interesting to note that, on this occasion, the relative entropy obtained was closer to the United States than the French level. Indeed, as can be inferred from Block and Walker (1988, table 3), the consensus on the subject among French economists was due to the fact that the great majority of them (more than two thirds!) disagreed with the monetarist position, rather than for the opposite reason.

There was also very substantial disagreement over proposition 6 ("A minimum wage increases unemployment"). Although the proposition has attracted a degree of consensus in almost all the countries where surveys of this type have been applied, this was not so among the Mexican economists, most of whom (55\%) came out against it.

Ranking alongside the above proposition in terms of relative entropy was proposition 21 ("Every central bank should include employment and/or economic growth among its objectives"), a subject that has been under discussion lately in Mexico. If this were so, this set of mandates would be similar to that of the United States Federal Reserve, which is obliged under the second section of the law governing it to pursue simultaneously the objectives of maximum employment, stable prices and moderate long-term interest rates. The main reason why the United States 
central bank has all these responsibilities at once is, of course, that it is not independent. The Mexican central bank is independent, however, and this may explain the divergence in views on this proposition.

We invite readers to continue reviewing the remaining propositions in tables 1 and 2 , where some rather unexpected results are to be found. To give just one example, $58 \%$ of respondents were in favour of statement 22 to the effect that genetically modified crops have a positive effect on the economy. In relative entropy terms, indeed, there was a degree of consensus on the issue.

\section{IV}

\section{Group response patterns}

At the end of section II there was a summary of respondents' characteristics in terms of age, sex, academic level, country where they obtained their highest academic qualification, and current place of employment. In this section we shall conduct an analysis of the response patterns obtained when some of these characteristics are controlled for. For example, are there generational differences? Is gender significant? Is it relevant that a third of respondents obtained their highest academic qualification abroad?

To find answers to questions of this type, it is first necessary to divide respondents into the two relevant subgroups and then establish, for each of the 30 propositions, the null hypothesis that the answers of both subgroups come from the same population. In this study, each of these hypotheses will be tested using the non-parametric Kolmogorov-Smirnov test, which has the great advantage over a number of other tests of not placing any restriction on the distribution of the responses. Table 3 presents the $p$ values of this test for each division (column) and each proposition (line). It may be worth recalling here that $p$, the probability value, is the empirical significance level of the test of hypothesis, so that when this exceeds the significance level $\alpha$ selected by the researcher (a level commonly set at $5 \%$ ), the null hypothesis that the answers come from the same population cannot be rejected.

The second column of table 3 presents the $p$ values for testing the null hypothesis that there are no generational differences; i.e., the hypothesis that the answers of economists aged up to 42 (the median age) and the answers of those older than this come from the same population. As the table shows, this hypothesis can be rejected at the 5\% significance level for just three questions. The first proposition on which there were was significant disagreement was 20 , concerning significant curtailment of union power. The divergence, it should be stressed, occurred particularly at the extremes of the distributions: while $9 \%$ of the youngest strongly disagreed with this statement, just $2 \%$ of the older economists did so; conversely, while $22 \%$ of the youngest strongly agreed, this proportion was 38\% among the oldest. Could this result indicate a more leftward-leaning ideological position among the younger economists? This claim could perhaps be made, especially in the light of the responses to the other two propositions for which there was an age divide. Number 26 asserted that the energy sector should be treated like any other sector where private investment was concerned, and while $60 \%$ of the younger economists disagreed or strongly disagreed with this, only $43 \%$ of older economists did so. Lastly, proposition 27 , which stated that the more independent the central bank, the better for economic stability and growth, was disagreed with by $42 \%$ of the younger economists and only $26 \%$ of the older ones.

The third column of table 3 divides respondents by sex. What it shows, strikingly, is that there is not a single proposition for which, using the KolmogorovSmirnov test, the null hypothesis of answers coming from the same population can be rejected. This finding is identical to that of Caminal and Rodríguez (2003) among Spanish economists, but is somewhat at variance with other studies. In the case of Canada, for example, there were divides between women and men for more than a fifth of the questions put by Block and Walker (1988). The greatest differences surfaced in relation to the proposition about the virtues of free trade, with women proving far more sceptical (Block and Walker, 1988 , p. 143). In our case, however, the $p$ value for proposition 1 was so high that we can safely say that the responses of male and female Mexican economists in relation to free trade showed no differences in distribution, which does not mean that there was 


\begin{tabular}{|c|c|c|c|c|c|c|}
\hline Proposition & $\mathrm{Age}^{\mathrm{a}}$ & Sex & $\begin{array}{l}\text { With/without } \\
\text { postgraduate } \\
\text { qualification }^{\text {b }}\end{array}$ & $\begin{array}{c}\text { Studied in } \\
\text { Mexico or } \\
\text { United States }^{\mathrm{c}}\end{array}$ & $\begin{array}{l}\text { Studied in } \\
\text { Mexico or } \\
\text { Europe }^{\mathrm{d}}\end{array}$ & $\begin{array}{c}\text { Working in public } \\
\text { or private } \\
\text { university }\end{array}$ \\
\hline 1 & 0.99 & 0.99 & 0.00 & 0.00 & 0.05 & 0.01 \\
\hline 2 & 0.44 & 1.00 & 1.00 & 0.99 & 0.85 & 0.24 \\
\hline 3 & 0.82 & 0.99 & 0.97 & 0.99 & 1.00 & 1.00 \\
\hline 4 & 0.97 & 0.96 & 0.14 & 0.00 & 0.91 & 0.95 \\
\hline 5 & 0.08 & 1.00 & 0.55 & 0.01 & 1.00 & 0.00 \\
\hline 6 & 0.97 & 1.00 & 0.13 & 0.00 & 1.00 & 0.06 \\
\hline 7 & 0.89 & 0.73 & 1.00 & 0.19 & 1.00 & 0.08 \\
\hline 8 & 0.53 & 1.00 & 1.00 & 0.00 & 0.98 & 0.64 \\
\hline 9 & 1.00 & 0.42 & 0.18 & 0.10 & 0.72 & 0.33 \\
\hline 10 & 0.09 & 1.00 & 1.00 & 0.00 & 1.00 & 0.31 \\
\hline 11 & 0.06 & 0.62 & 0.00 & 1.00 & 0.98 & 1.00 \\
\hline 12 & 0.56 & 1.00 & 0.03 & 0.01 & 0.37 & 0.12 \\
\hline 13 & 1.00 & 0.89 & 0.06 & 0.00 & 1.00 & 0.00 \\
\hline 14 & 1.00 & 0.53 & 0.76 & 0.58 & 0.71 & 0.98 \\
\hline 15 & 0.15 & 0.26 & 0.03 & 1.00 & 1.00 & 0.17 \\
\hline 16 & 1.00 & 0.65 & 1.00 & 1.00 & 1.00 & 0.11 \\
\hline 17 & 0.08 & 0.60 & 0.12 & 1.00 & 1.00 & 0.96 \\
\hline 18 & 0.73 & 1.00 & 0.15 & 0.80 & 1.00 & 0.84 \\
\hline 19 & 0.20 & 0.70 & 0.99 & 1.00 & 1.00 & 0.14 \\
\hline 20 & 0.01 & 0.23 & 0.10 & 0.72 & 1.00 & 0.02 \\
\hline 21 & 1.00 & 1.00 & 0.00 & 0.00 & 0.16 & 0.03 \\
\hline 22 & 1.00 & 0.17 & 0.79 & 0.00 & 1.00 & 0.18 \\
\hline 23 & 0.36 & 0.82 & 0.06 & 0.14 & 1.00 & 0.43 \\
\hline 24 & 1.00 & 0.99 & 0.95 & 0.11 & 0.62 & 0.05 \\
\hline 25 & 0.37 & 0.79 & 0.04 & 0.00 & 0.53 & 0.04 \\
\hline 26 & 0.01 & 0.56 & 0.31 & 0.01 & 0.96 & 0.04 \\
\hline 27 & 0.02 & 1.00 & 1.00 & 0.32 & 1.00 & 0.17 \\
\hline 28 & 0.96 & 1.00 & 0.98 & 0.80 & 0.99 & 0.38 \\
\hline 29 & 1.00 & 1.00 & 0.91 & 0.04 & 1.00 & 0.00 \\
\hline 30 & 0.21 & 1.00 & 0.88 & 0.97 & 0.96 & 1.00 \\
\hline
\end{tabular}

Source: Prepared by the author.

Division between those aged up to 42 (the median) and those older than this.

Division between those with a first degree at most and those with a postgraduate qualification (master's or doctorate).

Division only within the subgroup of respondents whose highest academic qualification was obtained in Mexico or the United States.

Division only within the subgroup of respondents whose highest academic qualification was obtained in Mexico or Europe.

e Only includes the subgroup of respondents who were working or studying at a university. The division is between public and private universities.

consensus; taken as a whole, indeed, the survey population displayed a high level of disagreement on the subject ( $\varepsilon=0.87$, as shown in table 2$)$.

The fourth column of table 3 divides respondents into those with a first degree at most and those with a postgraduate qualification (master's or doctorate). In this case there are six propositions for which the hypothesis that both sets of responses came from the same population can be rejected. These propositions are listed below, and the figures in brackets alongside them are the percentages of respondents with and without postgraduate qualifications who agreed or strongly agreed with them: 1 , on free trade $(33 \%$ and $55 \%)$; 11 , on negative taxes $(39 \%$ and $67 \%) ; 12$, on price controls $(42 \%$ and $29 \%) ; 15$, on government spending (52\% and $35 \%)$; 21 , on central bank objectives $(84 \%$ and $64 \%)$; and 25 , on the Tobin tax (83\% and 67\%). As can be seen when all the figures in brackets are 
compared, the views of respondents with postgraduate qualifications generally tended to be more conservative and closer to orthodox economic theory.

The fifth and sixth columns present the most surprising findings of this section. The first of these covers respondents whose highest qualification was obtained in a Mexican or United States university. The same thing was done in the sixth column, except that Europe was substituted for the United States. The contrast in the results is striking. While the $p$ values of the fifth column indicate that there were 13 propositions for which the null hypothesis could be rejected in the case of the Mexico-United States division, in the sixth column there is just one such proposition, number 1 . That is, those obtaining their highest qualification in a Mexican university had a very similar response pattern to those doing so in a European one, but a markedly different pattern from those obtaining it in a United States (or Canadian) university.

This deserves a closer look. The propositions on which there was an appreciable divide between those obtaining their highest qualification in Mexico and those obtaining it in the United States will now be presented, together with the percentages of respondents agreeing with each proposition in each subgroup (starting with Mexican graduates): number 1, on free trade $(39 \%$ and $75 \%)$; 4 , on cash payments and transferin-kind (53\% and $75 \%)$; 5 , on flexible exchange rates ( $69 \%$ and $89 \%)$; 6 , on the minimum wage $(38 \%$ and $70 \%) ; 8$, on income distribution $(96 \%$ and $91 \%) ;{ }^{3} 10$, on inflation ( $46 \%$ and $70 \%)$; 12 , on price controls $(37 \%$ and $21 \%) ; 13$, on rents ( $73 \%$ and $94 \%) ; 21$, on central bank objectives $(77 \%$ and $50 \%) ; 22$, on genetically modified crops $(53 \%$ and $78 \%$ ); 25 , on the Tobin $\operatorname{tax}(80 \%$ and $46 \%) ; 26$, on the energy sector $(44 \%$ and $64 \%$ ); and 29 , on public infrastructure (45\% and $28 \%$ ). For each of the propositions cited, economists graduating in the United States clearly took a position that was ideologically more conservative (or liberal, in the European sense of the term).

Lastly, the final column of table 3 establishes a division based on where respondents work. Although we assumed prior to the survey that this might prove to be a key variable in explaining the different response patterns, the fact is that we did not find appreciable differences in the answers given between, for instance, those working in universities and those working elsewhere (in the public or private sector) or, to give another example, those working in the public sector and those working in the private sector. The only major divides were found in the subgroup of respondents working in a public university and those doing so in a private university. As can be observed in the column mentioned, the equal distribution hypothesis can be rejected at the $5 \%$ significance level for nine propositions. We invite readers to note which these are, although it may be enough to point out that these propositions belong to the broader set of the 13 propositions on which those obtaining their highest qualification in Mexico were at variance with those obtaining it in the United States. This coincidence is not surprising either since, for example, an academic with a Mexican or European postgraduate qualification is far more likely to be working in a public university than a private one, while the opposite is true of those graduating from some United States university.

\section{$\mathrm{V}$}

\section{The micro/macro and positive/normative dichotomies}

In his influential work on economic methodology, Friedman (1953) argues that economic policy disagreements

\footnotetext{
${ }^{3}$ Proposition 8 elicited widespread assent in both groups; the difference lay in the fact that $65 \%$ of those obtaining their highest qualification in Mexico said they strongly agreed, while only $41 \%$ of the other group said the same.
}

between economists derive not so much from subjective differences as from different predictions about the consequences of taking action. Samuelson (1966), on the other hand, claims that agreement and disagreement among economists partly depend on the degree to which different value judgements converge and diverge; furthermore, Samuelson warns, forecasts themselves are ultimately subjective in character. 
In an effort to clarify the above, it is well worth turning to the hackneyed but serviceable classification of economic policies into those that are positive (descriptions, "this can be done") and those that are normative (prescriptions, "this ought to be done"). Samuelson would be at home with this distinction, but not Friedman, for whom all that distinguishes any economic policy is the effect it would have if adopted. Thus, for Friedman any economic proposition is essentially positive in character. The counterpart to this extreme posture is Myrdal (1954), who very eloquently upholds precisely the opposite thesis: economics is essentially normative in nature.

We took the intermediate point of view to establish, much as Kearl, Pope and others (1979) do, the hypothesis that positive propositions ought, at least on paper, to command greater consensus than normative ones. Similarly, and once again following the authors cited, we established a second hypothesis: microeconomic propositions, with their narrower scope, ought to command greater consensus than macroeconomic ones.

We put these two hypotheses to the test by constructing a matrix to divide the questions in the survey accordingly. This classification is necessarily subjective to some degree, as is illustrated by proposition 26 , which might have a positive character in many other countries but must be classified as normative in Mexico because of the strong feelings it arouses. With this caveat, we shall now present the matrix.

- Positive microeconomic propositions: 1, on free trade; 4, on cash payments and transfer-inkind; 6 , on the minimum wage; 13 , on rents; 14 , on pollution control; 24 , on subsidies to businesses; 28, on direct taxes; and 29, on public infrastructure.

- Normative microeconomic propositions: 8, on income distribution; 9, on economic regulation; 17, on income redistribution; 19 , on consumer protection; 20 , on unions; 22 , on genetically modified crops; and 26, on the energy sector.

- Positive macroeconomic propositions: 3, on monetary policy; 5 , on flexible exchange rates; 7 , on fiscal policy; 10, on inflation; 18 , on the Phillips curve; 23 , on the real business cycle; and 27, on central bank independence.

- Normative macroeconomic propositions: 2, on government employment; 11, on negative taxes; 12 , on price controls; 15 , on government spending; 16 , on countercyclical policy; 21 , on central bank objectives; 25 , on the Tobin tax; and 30 , on nature reserves.

This classification was used to test the hypotheses described earlier. This was done by means of a twofactor variance analysis ( $2 \times 2$ ANOVA), taking relative entropy as the dependent variable and examining variability within and between the subsamples. The $F$ statistic values obtained were 0.96 and 0.91 for micro/ macro and positive/normative dichotomies, respectively. Since the corresponding $p$ values of the $F$ statistic (with 1 and 26 degrees of freedom) were 0.34 and 0.35 , the null hypothesis that a single population generated the entropies observed in the subsamples could not be rejected at the $5 \%$ significance level. The same conclusion was obtained for the interaction between the two classes (the $p$ value obtained was 0.07 ). In plain language, the degree of consensus (or dissension) among Mexican economists does not seem to depend on the micro/macro character of the proposition, or on whether this is more positive than normative.

This result contrasts with that obtained by Kearl, Pope and others (1979), who found that among United States economists there was more consensus on the positive propositions than on the normative ones, and on the microeconomic ones than on the macroeconomic ones. The result also contrasts, although to a lesser degree, with that of Ricketts and Shoesmith (1992), who found that positive propositions (although not microeconomic ones) commanded greater agreement among British economists. Nonetheless, our finding seems to be the rule rather than the exception, since results identical to ours were obtained by Frey, Pommerehne and others (1984) in the case of Austrian, French, German and Swiss economists, and by Block and Walker (1988) in the case of Canadian economists.

Might there be any other elements that could help explain the areas of agreement and disagreement among Mexican economists? Rather than continue to speculate, we let the data "speak for themselves" by employing the multivariate statistical tool known as factor analysis. ${ }^{4}$ This technique was used to establish the common variability among the 30 propositions by identifying a small number of latent variables that were linear combinations of the original variables. This

\footnotetext{
${ }^{4}$ For example, see Peña (2002).
} 
analysis yielded two factors that accounted for the great bulk of the correlations between the questionnaire responses. ${ }^{5}$

The first factor proved to have positive correlations with the following propositions in particular (the weights are given in brackets): 1 , on free trade (0.59); 5 , on the effectiveness of flexible exchange rates $(0.58)$; 6 , on the minimum wage and unemployment $(0.53) ; 10$, on inflation as a monetary phenomenon $(0.52) ; 26$, on investment in the energy sector (0.57); and 27 , on the advantages of central bank independence (0.53). No proposition with a negative correlation had a weight of 0.50 or more.

The second factor proved to have positive correlations with the following propositions in particular: 8 , on more equal income distribution $(0.61)$; 17 , on income redistribution as a legitimate task of government $(0.50) ; 21$, on the inclusion of growth or

\section{VI}

\section{Conclusions}

This article has analysed the views expressed by a wide range of Mexican economists on a variety of economic propositions. Among the propositions that commanded the greatest assent were: equity in income distribution, vigorous use of antitrust and consumer protection laws, and the use of countercyclical fiscal policies. Among the propositions on which there was most dissension, meanwhile, were: private investment in the energy sector, the factors determining inflation, the minimum wage as a cause of unemployment and the objectives to be pursued by an independent central bank.

This paper has also analysed the response patterns of different groups of economists. No evidence was found of generational differences, nor were there

\footnotetext{
${ }^{5}$ The methodology followed might be of interest: (i) the value of the Kaiser-Meyer-Olkin statistic for the 30 questions was 0.80 , indicating that the propositions had significant common variability; (ii) consideration was given only to factors whose own values were greater than 1 (Kaiser's rule); (iii) the varimax rotation was used in such a way that each of the two factors affected its own corresponding variables but not the others; and (iv) the first factor and the second explained $45 \%$ and $28 \%$ of the variance, respectively.
}

employment among central bank objectives (0.50); and 25 , on the benefits of a Tobin tax (0.52). Once again, no proposal with a negative correlation had a weight of 0.50 or more.

We imagine that readers must have been as taken aback as we were upon seeing the two results above for the first time. The first factor can evidently be identified with strict orthodoxy and the second, at odds with the first, with a heterodoxy that smacks of Keynesianism. From the evidence set out above, and from a number of the findings described in section IV, a robust conclusion follows: rather than micro/macro and positive/normative dichotomies, it is the respondents' ideology, partially derived from their academic training, that emerges as the main conditioning element in the answers given by the 360 economists surveyed - something that would have seemed perfectly obvious to economists as diverse as Marx, Myrdal and Schumpeter. significant divides between the opinions of male and female economists. A very important factor, however, was the place where the individual's highest academic qualification was obtained. The response pattern of those obtaining it at universities in the United States (or Canada) was markedly to the right of the pattern found among those obtaining it at Mexican or European universities.

Section $\mathrm{V}$ of the study presented evidence that neither the positive or normative character of propositions nor their microeconomic or macroeconomic nature were elements that might help account for the degree of consensus or dissension among the respondents. Nonetheless, it also provided evidence that ideological outlook was a key factor in explaining correlations in replies.

To conclude, a final question needs to be asked: would conclusions similar to ours be obtained among the other economists of Latin America? This question will remain unanswered until colleagues in the other Latin American countries pick up the gauntlet.

(Original: Spanish) 
Anderson, M. (1998): Neoclassical Economics and the Australian Community: How Does the Public Arrange Economic Knowledge?, Melbourne Institute Working Paper, No. 25/98, Victoria, Australia, University of Melbourne.

Block, W. and M. Walker (1988): Entropy in the Canadian economics profession: sampling consensus on the major issues, Canadian Public Policy, vol. 14, No. 2, Toronto, Canada, University of Toronto Press, June.

Caminal, R. and D. Rodríguez (2003): La opinión de los economistas académicos en España, ¿consenso o segmentación?, Moneda y crédito, No. 217, Madrid, Fundación Santander Central Hispano.

Frary, R.B. (1996): Hints for designing effective questionnaires, Practical Assessment, Research and Evaluation, vol. 5, No. 3, College Park, Maryland, University of Maryland.

Frey, B.S., W.W. Pommerehne and others (1984): Consensus and dissension among economists: an empirical inquiry, American Economic Review, vol. 74, No. 5, Nashville, Tennessee, American Economic Association, December.
Friedman, M. (1953): The methodology of positive economics, Essays in Positive Economics, Chicago, University of Chicago Press.

Kearl, J.R., C.L. Pope and others (1979): A confusion of economists?, American Economic Review, vol. 69, No. 2, Nashville, Tennessee, American Economic Association, May.

Myrdal, G. (1954): The Political Element in the Development of Economic Thought, Cambridge, Massachusetts, Harvard University Press.

Peña, D. (2002): Análisis de datos multivariantes, Madrid, McGrawHill.

Ricketts, M. and E. Shoesmith (1992): British economic opinion: positive science or normative judgment?, American Economic Review, vol. 82, No. 2, Nashville, Tennessee, American Economic Association, May.

Samuelson, P.A. (1966): What economists know, in J. Stiglitz (ed.), The Collected Scientific Papers of Paul A. Samuelson, vol. 2, Cambridge, Massachusetts, The MIT Press. 